\title{
Long-term survival after coronary bypass surgery Comparison of various subsets of patients with general population
}

\author{
DAVID G GREENE, IVAN L BUNNELL, DJAVAD T ARANI, \\ GEORGE SCHIMERT, THOMAS Z LAJOS, ARTHUR B LEE, \\ RAVINDER N TANDON, $†$ WALTER T ZIMDAHL, JOHN M BOZER, \\ ROBERT M KOHN, JOHN P VISCO, DAVID C DEAN, GRETCHEN L SMITH \\ From the Departments of Medicine and Surgery, State University of New York at Buffalo, \\ and the Buffalo General Hospital, Buffalo, New York, USA
}

SUMMARY Life-table analysis of 1051 consecutive cases of isolated coronary bypass surgery. at the Buffalo General Hospital between 1973 and 1977 showed an estimated survival of 94 per cent at five years, equal to that of an age- and sex-matched group of the US population. Subsets of these patients divided according to sex, age, number of vessels narrowed, number of segments grafted, history of myocardial infarction, ejection fraction, and presence of unstable angina have estimated survivals not statistically less in any of these subsets than that of matched cohorts of the general population.

We, ${ }^{1-2}$ like others, ${ }^{3-9}$ have found improved survival in our more recent cohorts of patients undergoing coronary bypass surgery. In order to evaluate the more recent results, we are reporting the estimated survival of various subsets of patients in our experience with this surgery at the Buffalo General Hospital, particularly in the 1051 patients having had isolated coronary bypass surgery between 1 October 1973 and 30 September 1977, all followed up until 1 October 1978 . We are reporting on survival because it is an unequivocal end-point, reliably reported by many observers. Since we have no medically treated control subjects we are comparing our surgical patients with hypothetical subsets of the United States population, matched for age and sex, calculated from the US vital statistics for $1975 .{ }^{10}$

\section{Subjects and methods}

Between 1968 and 30 September 1977, 1468 operations which included coronary artery bypass surgery were performed at the Buffalo General Hospital by three of us (GS, TZL, ABL). Of these, 199 involved associated valve replacement, ven-

^Supported in part by a program-project grant from the National Heart, Lung and Blood Institute, and by gifts to the Buffalo General Hospital in memory of Cecil Kisiel.

†Present address: F/26 Shantinagar, Cantt, Kanpur, India.

Received for publication 10 October 1980 tricular resection, internal mammary implants, congenital heart disease, permanent cardiac pacemakers, simultaneous carotid artery surgery, repeat operations, or were done in patients on intra-aortic balloon counterpulsation. These 199 operations were considered complicated, and are excluded from further consideration. The remaining 1269 patients had operations between 1969 and 1977, and included patients in heart failure and patients with poor ventricular function. We have termed them isolated. More than 95 per cent had chest pain, but some had uncontrollable ventricular arrhythmias, and a few had had a recent myocardial infarction but were without symptoms at the time of surgery. Few operations were performed on patients over 70 years of age, or with left ventricular ejection fractions less than $0 \cdot 30$. In the case of repeat coronary bypass surgery the patient was included from the time of the first operation, and followed as if the second had not occurred.

Almost all of the patients were studied by coronary arteriography and left ventriculography at the Buffalo General Hospital by five of us (DTA, ILB, DGG, RNT, JPV). Selective coronary arteriograms were recorded on $35 \mathrm{~mm}$ cine film, with a $15 \mathrm{~cm}$ image amplifier, and ventriculograms, usually in two projections, on a $22 \mathrm{~cm}$ image amplifier (Picker X-ray Corp.). Large serial films were also taken in almost all cases, and selected films were sent to the operating room at the time of 
surgery. Almost all studies have included transaxial views. ${ }^{11} 12$ Ventriculograms were analysed for ejection fraction by a method previously described. ${ }^{13}$ A few patients had arteriography in other hospitals. Their films were reviewed at our hospital before surgery, and repeated if unsatisfactory. Vessels were considered significantly diseased and suitable for bypassing if they were $\mathbf{7 5}$ per cent narrowed in cross-sectional area $(50 \%$ in diameter), with adequate distal run-off. The criterion of 75 per cent narrowing in cross-section has been used in classifying patients as to the number of vessels critically involved. No patient had bypass surgery who did not have that degree of narrowing of at least one vessel, but in the latter part of the series vessels with less narrowing $(50 \%$ in cross-section or $30 \%$ diameter) have been selected for additional grafts.

Table 1 lists some of the characteristics of the patients. Patients were considered to have had a previous myocardial infarct on the basis of our own hospital records in many cases, on the reports of referring physicians, and also on the history given by the patient. Patients were classified as having unstable angina on the basis of new or progressive symptoms within the previous three months, angina at rest, angina waking them from sleep, angina with transient ischaemic changes in the electrocardiogram, or angina precipitating admission to a coronary care unit without findings of a fresh myocardial infarction. Patients with 75 per cent or greater narrowing in cross-sectional area of the left main coronary artery were classified as having left main disease. Most of them had additional narrowing in other vessels as well. The remaining patients were classified according to the number of major coronary trunks which were at least 75 per cent narrowed in cross-section.

All of the patients were followed up until 1 October 1978. Some were seen by one of us. The status of others was reported by their own physicians in response to an annual questionnaire we send to all referring physicians. Some patients report to us about their health annually by mail. Others we hear about from family or friends. Registered letters and direct telephoning are needed to find some patients; and for some who were elusive, on-the-spot reconnoitring has been necessary. On many the followup information has been voluminous, but on all we have as a minimum the date of death, or their survival until 1 October 1978, a minimum of one year after operation. All annual statements are based on a year running from 1 October to 30 September.

Statistical analysis was done by the life-table method $^{14}{ }^{15}$ and comparisons between groups made by determining a $z \operatorname{score}^{16}$ and 95 per cent con- fidence intervals. In addition, to compare the fiveyear survival of a group of patients with that of the general population each patient in the group was matched by age and by sex with a control from the general population. The number of deaths to be expected at five years in the control group was calculated from the US Vital Statistics for $1975,{ }^{10}$ amalgamating age in five-year groups. The ageing of the cohort over five years is included in this estimation. The number of deaths to be expected in five years in the patient group was taken from the life-table analysis of survival of the patients in that group. The significance of the differences was determined by $\chi^{2}$. Calculations have been done on an HP 67 pocket calculator using our own programs.

\section{Results}

The results are shown in Fig. 1 to 10 and in Tables 2,3 , and 4. Fig. 1 shows the annual number of patients undergoing bypass and their survival at 30 days and at one year from 1969-70 to 1976-77, and the 30-day survival for 1977-78. The steady increase in the annual number of operations has been accompanied by increases in the early and one-year survival rates. A step-like increase in both survival rates is suggested between 1974 and 1975. If one divides the series into the 218 patients whose operation was undertaken before 1 October 1973 and the 1051 patients whose operation was undertaken subsequently, the one-year survival is statis-

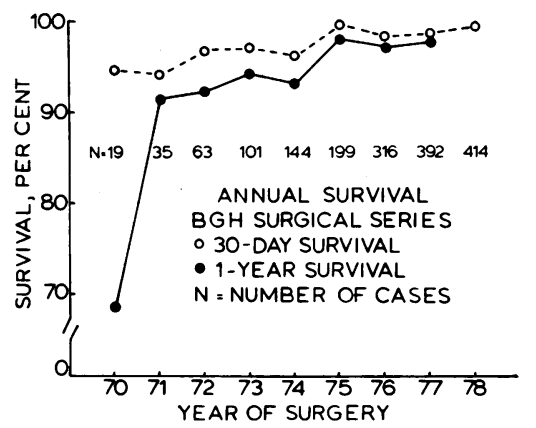

Fig. 1 Survival each year of the isolated coronary bypass patients who had operations between 1 October of the preceding year and 30 September of the year indicated. The 30-day survival is indicated by the open circles, and the one-year survival by the closed circles. $N$ gives the number of cases with operation each year. Whether the series is divided between 1973 and 1974 or between 1974 and 1975, the differences in survival between the early and late subsets are significant, both at 30 days and at one year. 


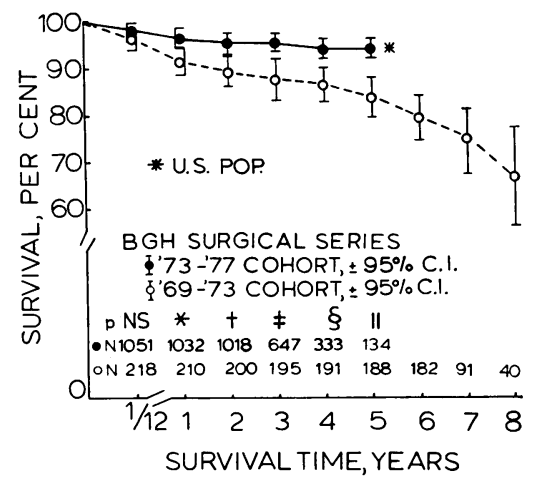

Fig. 2 Per cent survival plotted against time after operation for two cohorts of patients, those operated on before 1 October 1973, and those operated on between then and 30 September 1977. The time scale breaks between one month and one year. The vertical bars show the 95 per cent confidence intervals. The $p$ value is for the difference between the two groups at each time interval; $N S$ means not significant at $p=0.05$. The $N$ values show the number at risk at the beginning of each interval. The asterisk shows the expected survival at five years of a sample of the US population matched for age and sex with the 1051 patients in the more recent cohort. ${ }^{\star} p<0.02 ; \dagger p<0.01 ; \ddagger p<0.0005 ; \S p<0.005$; $\| p<0.0001$.

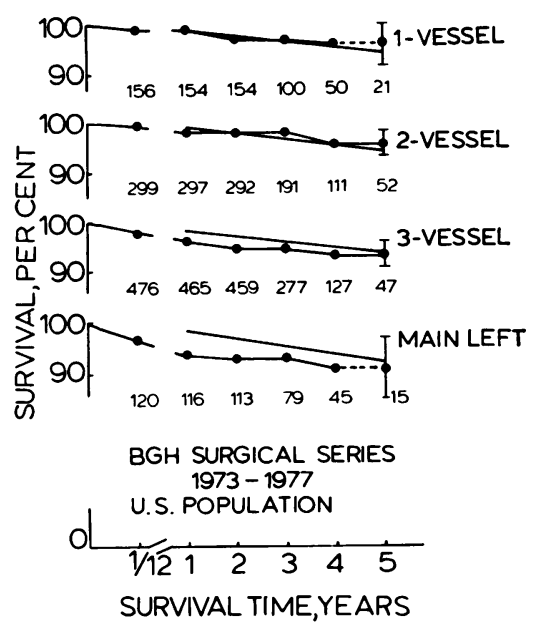

Fig. 3 Per cent survival plotted against time after operation for the patients in the 1973-1977 cohort categorised as to number of vessels critically narrowed. Subscripts give the number at risk at each time interval. The dotted lines indicate that fewer than 25 patients were at risk in determining the subsequent point. The straight solid line shows the survival of a sample of the US population matched for age and sex with each subset of these patients. The vertical bars indicate the 95 per cent confidence intervals of the subsets of patients. No difference is significant at five years.

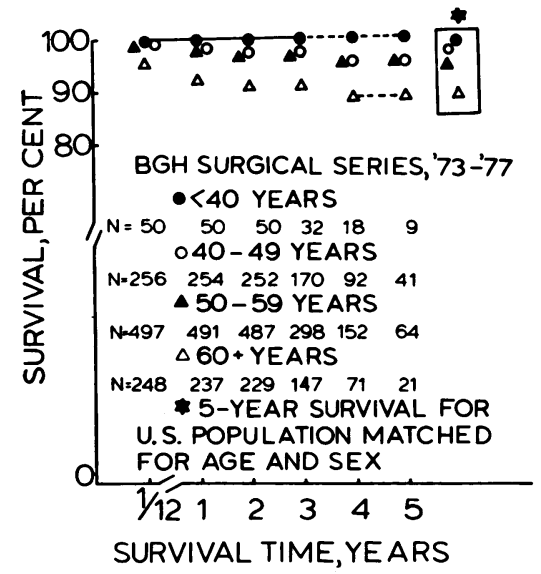

Fig. 5 Survival after operation of patients categorised as to age at the time of operation, plotted as in Fig. 2. The box under the star shows the survival of $a$ comparable group from the US population matched for age and sex. $N$ equals the number at risk in each interval. At five years no group of patients differs significantly from the comparable group of the general population. 


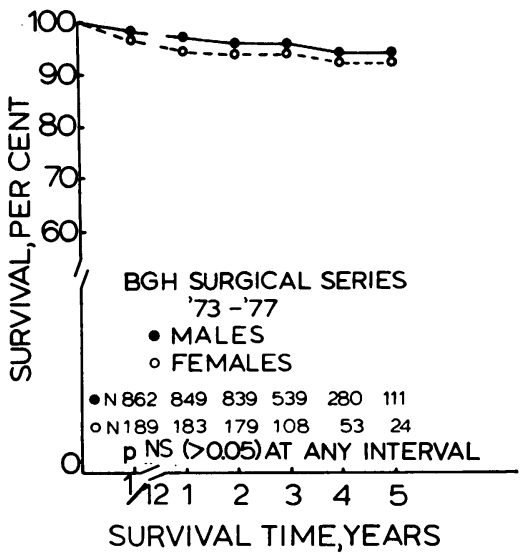

Fig. 6 Survival after operation of 862 males and 189 females plotted as in Fig. 2. The greatest difference is 2.6 per cent at one year.

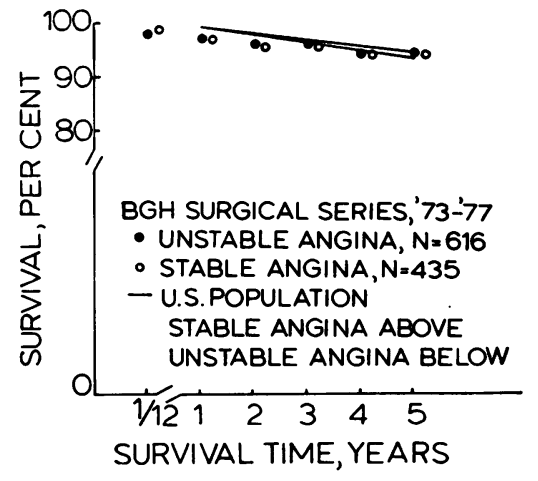

Fig. 8 Survival after operation of 616 patients with unstable angina, solid circles, and 435 patients whose angina was stable or who had no chest pain at the time of surgery, open circles. The expected survivals of the general population matched for age and sex with each group are drawn in as solid lines. The differences at five years between predicted and observed, and between stable and unstable angina, are not significant.

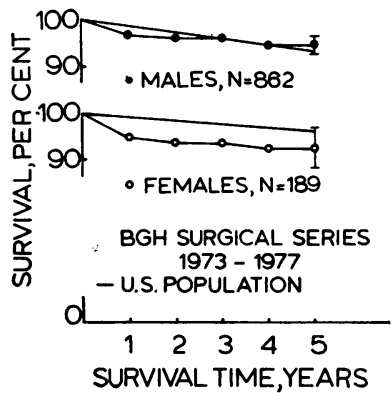

Fig. 7 Above, survival after operation of males plotted against time in years, and compared with the survival of an age-matched sample of the US population. Below, a similar plot for females. The difference between the surgical series and the US population at five years. 3.6 per cent, is not significant.

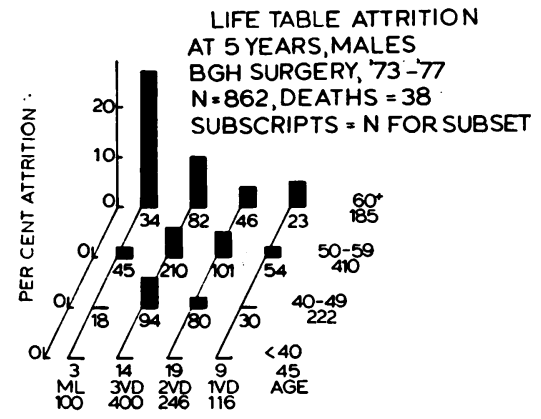

Fig. 9 Attrition five years after operation of 862 male patients at the Buffalo General Hospital operated on between 1973 and 1977, categorised as to age and number of vessels narrowed 75 per cent in cross-section. Many of the categories are small, and the individual differences are not statistically significant, but the tendency for the attrition to increase with more severe disease and in older patients is suggested. Expansion of the data as experience accumulates should permit a more precise estimate of chances of long-term survival of individual patients in the future. The anticipated $9 \cdot 1$ deaths in five years for the 34 patients over 60 with left main disease, while statistically distinct from the mortality of the group of 862 as a whole, does not differ sigficantly from the anticipated 4.1 deaths in an age-matched ingroup of 34 from the US population 


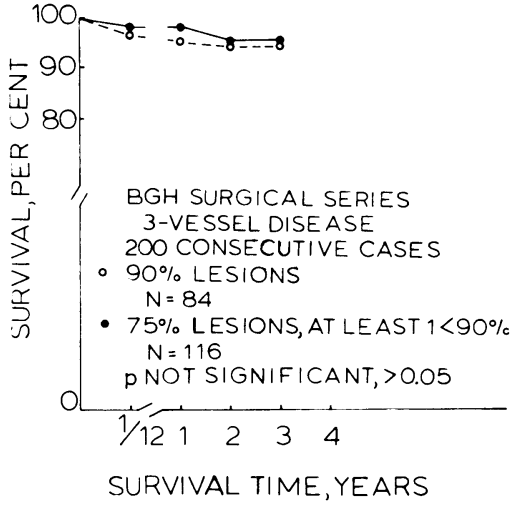

Fig. 10 Survival after operation of 200 consecutive cases categorised as three-vessel disease on the basis of 75 per cent narrowing in cross-section of each of three main trunks. They were divided into 84 with 90 per cent narrowings of three main trunks, and 116 with less than 90 per cent narrowing of at least one main trunk.

Table 1 Coronary bypass surgery at Buffalo General Hospital, 1969-1977

\begin{tabular}{|c|c|c|c|c|}
\hline & \multicolumn{2}{|c|}{$\begin{array}{l}\text { 1969-1973 } \\
\text { Cohort }\end{array}$} & \multicolumn{2}{|c|}{$\begin{array}{l}\text { 1973-1977 } \\
\text { Cohort }\end{array}$} \\
\hline & No. & Per cent & No. & Per cent \\
\hline Isolated bypass cases & 218 & 100 & 1051 & 100 \\
\hline 30-day mortality & 8 & $3 \cdot 7$ & 19 & $1 \cdot 8$ \\
\hline Males & 188 & 86 & 862 & 82 \\
\hline Previous myocardial infarction & 113 & 52 & 505 & 48 \\
\hline Unstable angina & 87 & 40 & 616 & 59 \\
\hline Left main lesions & 18 & 8 & 120 & 11 \\
\hline Three-vessel disease & 74 & 34 & 476 & 45 \\
\hline Two-vessel disease & 71 & 33 & 299 & 28 \\
\hline One-vessel disease & 55 & 25 & 156 & 15 \\
\hline
\end{tabular}

Table 2 Raw data for Fig 1

\begin{tabular}{lcllll}
\hline Year & $\begin{array}{l}\text { No. of } \\
\text { cases }\end{array}$ & $\begin{array}{l}\text { Death in } \\
\text { first } 30 \\
\text { days }\end{array}$ & $\begin{array}{l}\text { Mortality } \\
(\%)\end{array}$ & $\begin{array}{l}\text { Deaths in } \begin{array}{l}\text { Cumulative } \\
\text { next 11 } \\
\text { months }\end{array} \\
\text { mortality } \\
\text { at 1 year(\%) }\end{array}$ \\
\hline $1969-70$ & 19 & 1 & $5 \cdot 3$ & 3 & $21 \cdot 1$ \\
$1970-71$ & 35 & 2 & $5 \cdot 7$ & 1 & $8 \cdot 6$ \\
$1971-72$ & 63 & 2 & $3 \cdot 2$ & 3 & $7 \cdot 9$ \\
$1972-73$ & 101 & 3 & $3 \cdot 0$ & 3 & $5 \cdot 9$ \\
$1973-74$ & 144 & 6 & $4 \cdot 2$ & 4 & 6.9 \\
$1974-75$ & 199 & 1 & $0 \cdot 5$ & 3 & $2 \cdot 0$ \\
$1975-76$ & 316 & 6 & $1 \cdot 9$ & 4 & $3 \cdot 2$ \\
$1976-77$ & 392 & 6 & $1 \cdot 5$ & 3 & $2 \cdot 3$ \\
$1977-78$ & 414 & 3 & $0 \cdot 7$ & & \\
\hline
\end{tabular}

Table 3 Comparison of two cohorts, coronary bypass surgery, Buffalo General Hospital

\begin{tabular}{lcc}
\hline & $\begin{array}{l}1969-73 \\
\text { Cohort }\end{array}$ & $\begin{array}{l}1973-77 \\
\text { Cohort }\end{array}$ \\
\hline Number & 218 & 1051 \\
Mean age $(y)$ & 51 & 54 \\
Age range $(y)$ & $31-68$ & $27-73$ \\
Ejection fraction & 0.63 & 0.61 \\
Five-year survival $(\%) \mathrm{p}<0.0001$ & 85 & 94 \\
\hline
\end{tabular}

Table 4 Survival at five years, estimated by life-table method, of patients in the Buffalo General Hospital surgical series, 1973-1977; comparison with survival of similar groups from 1975 US population matched for age and sex

\begin{tabular}{|c|c|c|c|c|}
\hline Subset & $\begin{array}{l}\text { Number } \\
\text { in } \\
\text { subsets }\end{array}$ & $\begin{array}{l}\text { Survival } \\
\text { of subsets } \\
(\%)\end{array}$ & $\begin{array}{l}\text { Standard } \\
\text { error of } \\
\text { mean } \\
(\%)\end{array}$ & $\begin{array}{l}\text { Survival } \\
\text { of US } \\
\text { population } \\
(\%)\end{array}$ \\
\hline Whole series & 1051 & $94 \cdot 0$ & $1 \cdot 0$ & 93.6 \\
\hline Age less than 40 years & 50 & $100 \cdot 0$ & & $98 \cdot 8$ \\
\hline Age 40 to 49 years & 255 & $95 \cdot 7$ & $1 \cdot 7$ & $97 \cdot 2$ \\
\hline Age 50 to 59 years & 508 & $95 \cdot 3$ & $1 \cdot 2$ & $94 \cdot 0$ \\
\hline 60 or more years & 238 & $88 \cdot 2$ & $2 \cdot 5$ & $88 \cdot 2$ \\
\hline Males & 862 & $94 \cdot 3$ & $1 \cdot 0$ & $93 \cdot 1$ \\
\hline Females & 189 & $92 \cdot 6$ & $2 \cdot 2$ & $96 \cdot 1$ \\
\hline Left main disease & 210 & $91 \cdot 2$ & $3 \cdot 0$ & $92 \cdot 2$ \\
\hline Three-vessel disease & 476 & 93.5 & $1 \cdot 3$ & 93.6 \\
\hline Two-vessel disease & 299 & $95 \cdot 6$ & $1 \cdot 3$ & $94 \cdot 2$ \\
\hline One-vessel disease & 156 & $95 \cdot 6$ & $2 \cdot 1$ & 93.9 \\
\hline $\begin{array}{l}\text { Three-vessel disease, } \\
\text { males }\end{array}$ & 400 & 93.5 & 1.5 & $92 \cdot 7$ \\
\hline $\begin{array}{l}\text { Three-vessel disease, } \\
\text { females }\end{array}$ & 76 & $93 \cdot 1$ & $3 \cdot 0$ & 95.9 \\
\hline Stable angina pectoris & 435 & $93 \cdot 7$ & $1 \cdot 4$ & $94 \cdot 4$ \\
\hline Unstable angina pectoris & 616 & $94 \cdot 2$ & $1 \cdot 2$ & $93 \cdot 1$ \\
\hline $\begin{array}{l}\text { History of myocardial } \\
\text { infarct }\end{array}$ & 505 & $95 \cdot 0$ & $1 \cdot 2$ & $94 \cdot 0$ \\
\hline $\begin{array}{l}\text { No history of myocardial } \\
\text { infarct }\end{array}$ & 546 & $93 \cdot 1$ & $1 \cdot 3$ & $93 \cdot 3$ \\
\hline One to three grafts & 732 & $95 \cdot 2$ & $1 \cdot 0$ & $94 \cdot 0$ \\
\hline Four to seven grafts & 319 & $91 \cdot 2$ & $3 \cdot 1$ & $93 \cdot 0$ \\
\hline $\begin{array}{l}\text { Ejection fraction } 0.50 \\
\text { or more }\end{array}$ & 832 & $94 \cdot 0$ & $1 \cdot 0$ & 93.6 \\
\hline $\begin{array}{l}\text { Ejection fraction less } \\
\text { than } 0.50\end{array}$ & 203 & $94 \cdot 7$ & $1 \cdot 7$ & $93 \cdot 8$ \\
\hline
\end{tabular}

tically better in the later group $(\mathrm{p}<0.001)$. The onemonth survival is also better in the later group. Moving the division a year later has no important effect on these findings. This difference in survival between the early 218 patients and the later 1051 patients is increasingly significant the longer the patients are followed (Fig. 2), and at five years is highly significant $(\mathrm{p}<0.0001)$.

These results immediately raise the question of possible differences in selection with the passage of 
time. Table 3 shows the comparisons between the earlier and later series as to age and ejection fraction. The more recent group does not seem to have been a more favourable one in respect of selection.

The remaining results deal with the 1051 patients who had operation between 1 October 1973 and 30 September 1977. As Table 4 shows, in the subsets of these surgical patients, survival at five years does not differ significantly from that of subsets of the US population in 1975 matched for age and sex. In 13 subsets the survival at five years equalled or exceeded that of the general public; in eight it was less. For all 21 subsets the five-year survival for the US population matched for age and sex fell within the 95 per cent confidence intervals. In only five subsets did the survival of the general public lie more than one standard error of the probability of survival away from the survival of the surgical patients. These patients were 50 to 59 years of age, men and women, with one to three grafts, and those with two-vessel disease. Even so the $\chi^{2}$ analysis showed that the differences were not statistically significant at the 5 per cent level.

Fig. 3 shows the actuarial survival curves of patients with disease of the left main coronary artery and of patients with three-vessel, two-vessel, and one-vessel disease. In each case the survival of a group of the US population matched for age and sex is also indicated. The survival curve for patients with left main disease runs below that of the general public, but approaches it as time goes on, and is not statistically different at five years. Only 15 patients were at risk in the fifth year. The survival curve for patients with three-vessel disease also runs below that of the general public, but the curves converge at five years. In patients with two-vessel and onevessel disease the survival curves differ little from those of the general public. Fig. 4 shows that the survival curves for one- and two-vessel disease are slightly higher than those for three-vessel and left main disease. The only statistically significant differences between categories are the better survival of the patients with two-vessel disease as compared with three-vessel disease at one month and at two and three years.

As can be seen in Fig. 5, age has an important effect on survival after coronary bypass surgery, but it accords with the effect of age on survival in general. No deaths were noted in patients under $\mathbf{4 0}$ years of age, but the numbers at risk in the fourth and fifth years were small. Patients in the fifth decade survived 1.5 per cent less well than the general public and patients in the sixth decade survived 1.3 per cent better than the general public. Neither difference is significant. Survival of the older patients equalled that of the general public. Fig. 6 shows that the survival curve for women runs consistently but not significantly below that of men. Table 4 and Fig. 7 show the relation of the survivals at five years to those of the general public according to sex. Though in the general population more women survived than men, this relation did not hold for the patients undergoing operation. The female subset is the one in which the survival of the age-matched sample of the US population comes nearest to lying outside the 95 per cent confidence interval.

Fig. 8 and Table 4 show that in this series of patients whether or not angina was unstable had little effect on survival after operation for the first five years. In Table 4 one can also note that a history of a myocardial infarction or the presence of an ejection fraction above or below 0.5 had insignificant effects on survival for five years in this series. Patients with one to three grafts had a slightly but insignificantly better survival at five years than the US population or patients with four to seven grafts.

Further analysis of our series by breaking subgroups into more specific subcategories is frustrated by dwindling numbers and hence the lower reliability of the results. Table 4 shows that when threevessel disease is divided by sex, the difference in survival is negligible $(0.4 \%)$. Fig. 9 shows what sort of analysis can be tried when more data and longer follow-up periods are available. In this figure the male cases are categorised as to age group and number of vessels involved, and the expected mortality at five years from life-table analysis is plotted on the third axis.

\section{SEVERITY OF CORONARY NARROWING}

Our criterion for important narrowing of a coronary artery, severe enough to be counted as a diseased vessel, and severe enough in the appropriate clinical situation to warrant a bypass graft, is 75 per cent in cross-sectional area or 50 per cent in diameter. This is the same criterion used in the Veterans Administration cooperative study, ${ }^{17}$ and in several other series, ${ }^{18} 19$ but is less stringent than that used in many other clinical studies, ${ }^{20-25}$ where 90 per cent cross-section $(70 \%$ diameter) was the criterion used. To test the influence on survival of this broader criterion for the selection of patients for operation we reviewed 200 consecutive patients in the '73-'77 series originally classified as three-vessel disease on the basis of at least 75 per cent narrowing of the cross-section of the lumen. In the review all 200 still qualified as three-vessel disease, but 84 were found to fit the more rigorous criterion of 90 per cent narrowing of luminal crosssection in all three main trunks. Of the other 116 
many had 90 per cent narrowing of one or two main trunks, but all had less than 90 per cent narrowing of at least one of them. The actuarial survival for the two groups in Fig. 10 shows no significant differences for the three years they have been followed. Survival at three years was 95.3 per cent for those with less than 90 per cent narrowing of at least one vessel, 93.8 per cent for the group meeting the stricter criterion.

\section{CAUSES OF DEATH}

In the first 30 days after operation 19 patients died. Eight had myocardial infarction, three had congestive heart failure, and two died suddenly. There were three technical difficulties at operation: an air embolism, an uncontrollable haemorrhage, and a dissecting haematoma. Sepsis was the primary cause of death in one patient, and contributed to the death of three others primarily classified otherwise. Two patients died of causes not primarily caused by either coronary artery disease or bypass surgery: one of necrosis of a pituitary tumour and the other of myasthenia gravis. Thirty-one deaths occurred later in the period of observation, which ranged up to five years. Eight died of congestive heart failure, and five of recurrent myocardial infarction. Sepsis was the primary cause of death in four, and sudden death occurred in two. The cause of death could not be ascertained in five patients, and three had cancer, with primaries in the lung, oesophagus, and larynx. One death each was caused by cerebral thrombosis, dissecting haematoma, suicide, and ulcerative colitis. In summary the early deaths were related to or precipitated by the operation. Three-quarters of the late deaths were related to the operation or to the underlying arterial disease and its effect on the heart and one-quarter to unrelated disease.

\section{Discussion}

Evolution of our surgical technique for coronary bypass surgery can be divided into three phases. The first phase, from 1968 to 1973, involved normothermic perfusion, and the pump oxygenator was primed with heparinised blood. Myocardial protection was achieved through fibrillation perfusion with apical venting of the left ventricle, and the sutures were interrupted. The internal mammary artery was used frequently. In the second period, from 1974 to 1975 , a bloodless prime was used with moderate hypothermia of the blood from $28^{\circ}$ to $30^{\circ} \mathrm{C}$. Periodic defibrillation between distal anastomoses was carried out and a continuous suture technique was used. In the third phase, which began at the beginning of 1976 and has continued to the present time, cold cardioplegia was used followed by hyperkalaemic cardioplegia. We now use a combination of these techniques of cardioplegic myocardial protection, usually with the addition of methylprednisolone at high intracardiac concentration (approximately $1 \mathrm{mg} / \mathrm{g}$ cardiac tissue). A prospective randomised study carried out in $1976^{26}$ showed the improved myocardial protection afforded by either cold cardioplegia or hyperkalaemic cardioplegia over the fibrillation perfusion.

Survival of the general population of the United States has been criticised as an inappropriate standard for comparison of the results of coronary bypass surgery. Surgical candidates are carefully screened to eliminate many acute and chronic diseases which contribute to the mortality of the general public. But as pointed out by Kirklin et al. ${ }^{7}$ the survival of the general population provides a less elastic standard against which to measure surgical results than medical treatment, with which many believe the results are also improving. ${ }^{27} \mathrm{We}$ have not found any reports of medical treatment of angiographically demonstrated multivessel coronary atherosclerosis with five-year survival equal to the general population. ${ }^{1}$ The closest approach is the series of Kent et al. ${ }^{28}$ of mildly symptomatic and asymptomatic patients treated medically. They showed an annual mortality for two years of 2.4 per cent in patients with two- and three-vessel disease, compared with the annual mortality of 1.1 per cent for five years in our surgical series ( 775 patients with two- and three-vessel disease, most of whom had significant angina).

One can also question the use of the general population of the United States as a reference for our series which is largely from western New York State, and predominantly white. The survival of whites in western New York is not available with the same accuracy as that of the whole population, and the comparison is less reliable. We have therefore used data which are matched only for age and sex. If the 1051 patients are matched for age and sex with whites from the US population, the predicted five-year survival is 93.9 per cent instead of 93.6 per cent predicted on the basis of all races. In either case the 94.0 per cent five-year survival of the 1051 surgical patients equals the comparison group. We also compared all our subgroups with the US vital statistics for whites instead of for all races, and still found no differences which were significant at the 5 per cent level.

Mathur et al. ${ }^{29}$ have pointed out that the equalisation of survival after surgery of subsets of patients with differing survival rates on medical management implies that surgery improves survival. The equalisation of survival rates in our series of patients 
in different subsets supports their thesis. The relevant subsets in our series are males and females, number of vessels narrowed significantly, number of segments grafted, history of myocardial infarction, stable or unstable angina, and, within the context of our own series, ejection fraction. Our series includes only 25 patients with ejection fractions less than 0.30 . The failure of low ejection fraction in our series to correlate with diminished survival is contrary to the experience of most other groups. Mathur et al., ${ }^{29}$ however, have reported results similar to ours.

The patients in our surgical series represent a favourable subset of patients with coronary artery disease in that they have been selected largely with good ventricular function and largely under 70 years of age, and with potentially graftable vessels with good run-off. The patients in the more recent cohort have the further advantage of good myocardial protection during cardiopulmonary bypass, and as many grafts as necessary to revascularise as much of the myocardium as possible. These data identify a large population of patients whose potential life expectancy can be increased by the addition of surgical treatment to medical management.

Age appears to be the most important factor influencing long-term survival after surgery in our 1973-77 cohort and, though its effect appears to be non-specific, a trend in the data appears when one plots the influences of age and number of vessels involved on five-year attrition (100 minus per cent survival) for the men in our series as is seen in Fig. 9. The numbers in the 16 subsets are variable, and too small for any conclusions in several. Of the subsets with some attrition recorded, only that subset over 60 years of age with left main disease differs significantly from the set of 862 men, and even this subset is not statistically different from the US population matched for age and sex $\left(\chi^{2}\right)$. None the less the trend of higher mortality in the older ages and with more vessels involved is suggested.

Others have attempted to identify subgroups whose survival is favourably influenced by surgery. ${ }^{9} 30$ DeRouen et $a .^{30}$ have analysed the medical and surgical results in the Seattle Heart Watch in a series of subgroups, and have reported improved survival in surgically managed rather than medically managed patients 48 years old or older, with two- and three-vessel disease, with no heart murmur, with no history of congestive heart failure, with no cardiomegaly, with no ventricular arrhythmias on the resting electrocardiogram or not on diuretics. In analysing five-year survival of 1718 patients, Hoffmann et al. ${ }^{9}$ have found important prognostic significance in the severity of coronary narrowing, age, left ventricular end-diastolic pressure, plasma cholesterol levels, and the presence or absence of severely impaired left ventricular function. They have prepared a table summarising the relations between these variables, predicting different survivals at five years from 20 per cent to 99 per cent. They also found some influence on predicted survival of systolic blood pressure, previous myocardial infarction, and previous stroke.

In 1977 both we ${ }^{2}$ and Ochsner ${ }^{31}$ compared survival in subgroups of surgical patients with that of the general population. Lawrie et $a{ }^{32}$ showed that the long-term survival in several subsets of their surgical patients approximated that of comparable subsets of the general population, and in subsets with good ventricular function the surgical patients did as well or better. In evaluating an extensive experience with coronary bypass surgery, Kirklin et al. ${ }^{7}$ have compared the five-year survival with that of the general population, and found that for onevessel disease the survival is statistically the same as that of the general population matched for age, sex, and race. At five years, patients with left main disease, three-vessel disease, and two-vessel disease fell $7 \cdot 7,6 \cdot 1$, and $7 \cdot 4$ per cent below the matched general population. They included patients operated on in the years 1970-79, and the surgical mortality may have been higher in the early years than it is currently. Cameron et al. ${ }^{4}$ have published the longterm survival experience with coronary bypass surgery of 850 consecutive patients operated on in 1971-73. The seven-year survival of these patients, 89.4 per cent, included within one standard error that of an age- and sex-matched group of the US population, 90.4 per cent. Their series, from an earlier date and followed two years longer than ours, is similar to ours in reflecting no significant survival differences according to single, double, or triple bypass grafts, and slightly but not statistically significantly better survival of men than women. On the other hand, their differences in survival according to ejection fraction and presence of left main disease were more distinct than ours.

\section{Conclusions}

Life-table analysis of survival of our patients having coronary bypass surgery between 1973 and 1977 shows that estimated survival at five years is statistically indistinguishable from that of the US general population matched for age and sex. The same statement holds true when applied to subsets of our patients divided according to number of vessels critically narrowed, sex, age, number of segments grafted, history of myocardial infarctions, ejection 
fraction, or presence of unstable angina. Though the US population matched for age and sex is not an ideal control group for our surgical series it does serve as a reference point which is independently derived, and not so far equalled by medical management in any reported series of arteriographically diagnosed patients with multivessel disease. These findings provide additional support for the impressive mass of data now indicating that the best results in coronary artery disease come from surgical revascularisation supplemented by all applicable medical measures. They also permit the confident recommendation of coronary bypass surgery for many different subsets of patients based on its capacity to prolong life as well as to ameliorate symptoms.

\section{References}

1 Greene DG, Bunnell IL, Arani DT, et al. Preservation of myocardium by coronary bypass surgery: the effect on survival. In: Hurst JW, ed. Update II : the heart: bypass surgery for obstructive coronary disease. New York: McGraw-Hill, 1980; 159-74.

2 Greene DG, Bunnell IL, Arani DT, et al. Longterm survival after coronary bypass surgery. Miami, Florida: Exhibit, Annual Meeting, American Heart Association, 1977.

3 Hurst JW, King SB III, Logue RB, et al. Value of coronary bypass surgery. Am $\mathcal{f}$ Cardiol 1978; 42: 308-29.

4 Cameron A, Kemp HG Jr, Shimomura S, et al. Aortocoronary bypass surgery. A 7-year follow-up. Circulation 1979; 60, suppl I: 9-13.

5 Kouchoukos NT, Oberman A, Karp RB. Results of surgery for disabling angina pectoris. In: Rahimtoola $\mathrm{SH}$, ed. Coronary bypass surgery. Philadelphia: F A Davis, 1977: 157-66.

6 European Coronary Surgery Study Group. Coronary-artery bypass surgery in stable angina pectoris: survival at two years. 1979; Lancet i: 889-93.

7 Kirklin JW, Kouchoukos NT, Blackstone EH, Oberman A. Research related to surgical treatment of coronary artery disease. Circulation 1979; 60: 1613-8.

8 Tyras DH, Barner HB, Kaiser GC, et al. Long-term results of myocardial revascularization. $\mathrm{Am} \mathcal{F}$ Cardiol 1979; 44: 1290-6.

9 Hoffmann RG, Blumlein SL, Anderson AJ, Barboriak JJ, Walker JA, Rimm AA. The probability of surviving coronary bypass surgery. Fiveyear results from 1,178 patients. $\mathcal{F} A M A 1980 ; 243$ : 1341-4.

10 Vital Statistics of the United States, 1975. Vol IIMortality Part A. Hyattsville, Maryland: US Department of HEW, PHS, National Center for Health Statistics, 1979.

11 Bunnell IL, Greene DG, Tandon RN, Arani DT. The half-axial projection: a new look at the proximal left coronary artery. Circulation 1973; 48: 1151-6.

12 Arani DT, Bunnell IL, Greene DG. Lordotic right posterior oblique projection of the left coronary artery. Circulation 1975; 52: 504-8.

13 Greene DG, Carlisle R, Grant C, Bunnell IL. Estimation of left ventricular volume by one-plane cineangiography. Circulation 1967; 35: 61-9.

14 Cutler SJ, Ederer F. Maximum utilization of the life table method in analyzing survival. $f$ Chronic Dis 1958; 8: 699-712.

15 Anderson RP, Bonchek LI, Grunkemeier GL, Lambert LE, Starr A. The analysis and presentation of surgical results by actuarial methods. F Surg Res 1974; 16: 224-30.

16 Anderson RP, Rahimtoola SH, Bonchek LI, Starr A. The prognosis of patients with coronary artery disease after coronary bypass operations. Timerelated progress of 532 patients with disabling angina pectoris. Circulation 1974; 50: 274-82.

17 Murphy ML, Holtgren $\mathrm{HN}$, Detre K, et al. Treatment of chronic stable angina. A preliminary report of survival data of the randomized Veterans Administration cooperative study. $N$ Engl f Med 1977; 297: 621-7.

18 Spencer FC, Isom OW, Glassman E, et al. The long-term influence of coronary bypass grafts on myocardial infarction and survival. Ann Surg 1974; 180: 439-51.

19 Kloster FE, Kremkau EL, Ritzmann LW, Rahimtoola SH, Rösch J, Kanarek PH. Coronary bypass for stable angina. A prospective randomized study. N Engl f Med 1979; 300: 149-57.

20 Fischl SJ, Herman MV, Gorlin R. The intermediate coronary syndrome. Clinical, angiographic and therapeutic aspects. $N$ Engl $\mathcal{f}$ Med 1973; 288: 1193-8.

21 Manley JC, King JF, Zeft HJ, Johnson WD. The "bad" left ventricle. Results of coronary surgery and effect on late survival. F Thorac Cardiovasc Surg 1976; 72: 841-8.

22 Conti R, Brawley RK, Griffith LSC, et al. Unstable angina pectoris: morbidity and mortality in 57 consecutive patients evaluated angiographically. $\mathrm{Am}$ f Cardiol 1973; 32: 745-50.

23 Mathur VS, Guinn GA, Anastassiades LC, et al. Surgical treatment for stable angina pectoris. Prospective randomized study. $N$ Engl f Med 1975; 292: 709-13.

24 Levine FH, Gold HK, Leinbach RC, Daggett WM, Austen WG, Buckley MJ. Safe early revascularization for continuing ischemia after acute myocardial infarction. Circulation 1979; 59-60, suppl I: 5-9.

$25 \mathrm{McNeer}$ JF, Starmer CF, Bartle AG, et al. The nature of treatment selection in coronary artery disease. Experience with medical and surgical treatment of a chronic disease. Circulation 1974; 49: 606-14.

26 Schachner A, Schimert G, Lajos TZ, et al. Comparison of myocardial preservation techniques for aortocoronary bypass surgery. If Surg Res 1977; 22: 242-63.

27 Stern MP. The recent decline in ischemic heart 
disease mortality. Ann Intern Med 1979; 91: 630-40

28 Kent KM, Rosing DR, Borer JS, Seides SF, Epstein SE. The natural history of asymptomatic or mildly symptomatic patients with coronary artery disease (abstract). Clin Res 1979; 27: 179A.

29 Mathur VS, Hall RJ, Garcia E, deCastro CM. Improved longevity following coronary artery bypass (CAB) surgery: is it real or is it an illusion? (abstract). Am f Cardiol 1980; 45: 418.

30 DeRouen TA, Hammermeister KE, Dodge HT. Comparisons of the effects on survival of coronary artery surgery in subgroups of patients from Seattle Heart Watch (abstract). Am f Cardiol 1980; 45 : 418.
31 Ochsner JL. The superiority of the internal mammary artery as a coronary bypass graft. Syllabus. The first decade of bypass graft surgery for coronary artery disease. Cleveland, Ohio: Cleveland Clinic Foundation, 1977.

32 Lawrie GM, Morris GC Jr, Howell JF, Tredici TD, Chapman DW. Improved survival after 5 years in 1,144 patients after coronary bypass surgery. $A m \mathcal{F}$ Cardiol 1978; 42: 709-15.

Requests for reprints to Professor David G Greene, 100 High Street, Buffalo, New York 14203, USA. 